\title{
Organ culture of rabbit ileum as a model for the investigation of the mechanism of intestinal damage by enteropathogenic Escherichia coli
}

\author{
R M BATT, C A HART, L McLEAN, AND J R SAUNDERS \\ From the Departments of Veterinary Pathology, Medical Microbiology and Microbiology, University of \\ Liverpool, Liverpool
}

SUMMARY Organ culture of rabbit ileum has been established as a model for the investigation of the mechanism of intestinal damage by enteropathogenic Escherichia coli (EPEC). Loops of rabbit ileum were filled in vivo with saline, non-enteropathogenic P-fimbriate $E$ coli (PFEC), or EPEC. After 45 minutes the loops were washed, then mucosal biopsies were taken and cultured for up to 48 hours. The earliest changes discernable by electron microscopy were observed at 18 hours postinfection, at which time EPEC were closely adherent to the surface of enterocytes at the base of microvilli, some of which were elongated. By 24 hours postinfection there were large areas of brush border effacement with pedestal formation around the EPEC. No such damage was seen in biopsies from the control loops (saline, PFEC), and intracellular ultrastructure was extremely well preserved in all preparations for up to 48 hours. While there were no differences at eight hours, biochemical analyses at 24 hours postinfection showed a marked increase in the release of brush border enzymes into the culture medium from EPEC-infected explants compared to explants from the control loops. These findings provide morphological and biochemical evidence for damage to the microvillus membrane by EPEC, and validate organ culture of rabbit ileum as a model for the investigation of EPEC-pathogenicity.

Escherichia coli can cause clinical disease in man and animals by at least three different mechanisms. ${ }^{1}$ The modes of action of enterotoxigenic and enteroinvasive $E$ coli in the pathogenesis of diarrhoea are relatively well understood, and specific in vitro procedures have been developed for the investigation of these organisms. ${ }^{23}$ More recently, a third mechanism which involves destruction of microvilli by enteropathogenic $E$ coli (EPEC) has been described, ${ }^{+7}$ but the gene products responsible and the mechanism of damage are unknown.

Enteropathogenic $E$ coli were recognised initially as belonging to specific $\mathrm{O}$-serogroups that were associated with outbreaks of diarrhoea in man earlier this century. ${ }^{89}$ The disease mechanism was unknown, however, until ultrastructural damage to the brush border was reported in rabbits infected with EPEC (015). ${ }^{4}$ Bacteria were closely adherent to the enterocyte surface with pedestal formation and brush

Address for correspondence: Dr R M Batt. Department of Veterinary Pathology, University of Liverpool. PO Box 147. Liverpool L69 3BX. UK. Received for publication 5 March 1987. border effacement. Similar findings in subsequent studies of children infected with EPEC $(0125,0119$, $0111)^{5}$ have indicated that brush border damage is also relevant to the development of EPEC-induced diarrhoea in man.

These changes have been reported not only in the small intestinal mucosa of rabbits, ${ }^{+11}$ but also in naturally and experimentally infected calves, " and in gnotobiotic pigs,${ }^{12}$ all of which have been proposed as models for EPEC-induced damage to the small intestine. As there are practical constraints in the use of experimental animals, however, organ culture of rabbit ileum has been validated as an assay system for the investigation of the molecular biology of EPECpathogenicity.

\section{Methods}

BACTERIA

The strain of enteropathogenic Escherichia coli (EPEC) used in these experiments $\left(0111 \mathrm{a}, \mathrm{bH}^{-}\right)$was isolated from a child with gastroenteritis ${ }^{7}$ this strain 
has been shown not to produce heat labile toxins, heat stable toxins or verotoxin, but did show localised adhesion on Hep-2 cells. The non-enteropathogenic strain of P-fimbriate $E$ coli (PFEC) was obtained from Dr D C Old, University of Dundee. Both bacteria were stored at $-70^{\circ} \mathrm{C}$ in glycerol broth. Immediately before each experiment, bacteria were cultured aerobically for 18 hours on blood agar and were then removed and suspended in MEM (Gibco Europe Ltd, Uxbridge, UK) at a final concentration of approximately $10^{7} \mathrm{cfu} / \mathrm{ml}$ for introduction into ileal loops.

\section{MODEL SYSTEM}

Adult New Zealand White rabbits that had been fasted overnight were anaesthetised with Valium (Roche Products Ltd, Welwyn Garden City, UK) and Hypnorm (Crown Chemical Co Ltd, Lamberhurst, UK). In each animal, $30 \mathrm{~cm}$ of distal ileum were flushed with sterile isotonic saline, and three randomised $5 \mathrm{~cm}$ loops were filled with isotonic saline, PFEC, or EPEC. After 45 minutes the loops were washed with isotonic saline. Mucosal biopsies were then taken with fine scissors and maintained for up to 48 hours on stainless steel grids, each supported in contact with culture medium in a sterile plastic dish. ${ }^{13}$

Culture medium consisted of modified Trowell's solution ${ }^{14}$ (by volume: $65 \%$ Trowell's T8, 20\% NCTC $135,15 \%$ fetal calf serum; (Gibco, UK) containing benzyl penicillin $(60 \mathrm{mg} / \mathrm{l}$; Glaxo, Uxbridge, UK) and L-glutamine ( $2 \mathrm{mmol} / \mathrm{l}$; Gibco, UK). The dishes were equilibrated and maintained throughout the culture period at $37^{\circ} \mathrm{C}$ in an atmosphere of $95 \%$ oxygen and $5 \%$ carbon dioxide. At timed intervals, cultured ileal explants were removed and processed for electron microscopy, or all explants and culture medium in a dish were removed for enzyme assay.

\section{ULTRASTRUCTURAL, STUDIES}

Tissue for electron microscopy was fixed in cacodylate buffered $2.5 \%(\mathrm{v} / \mathrm{v})$ glutaraldehyde. These

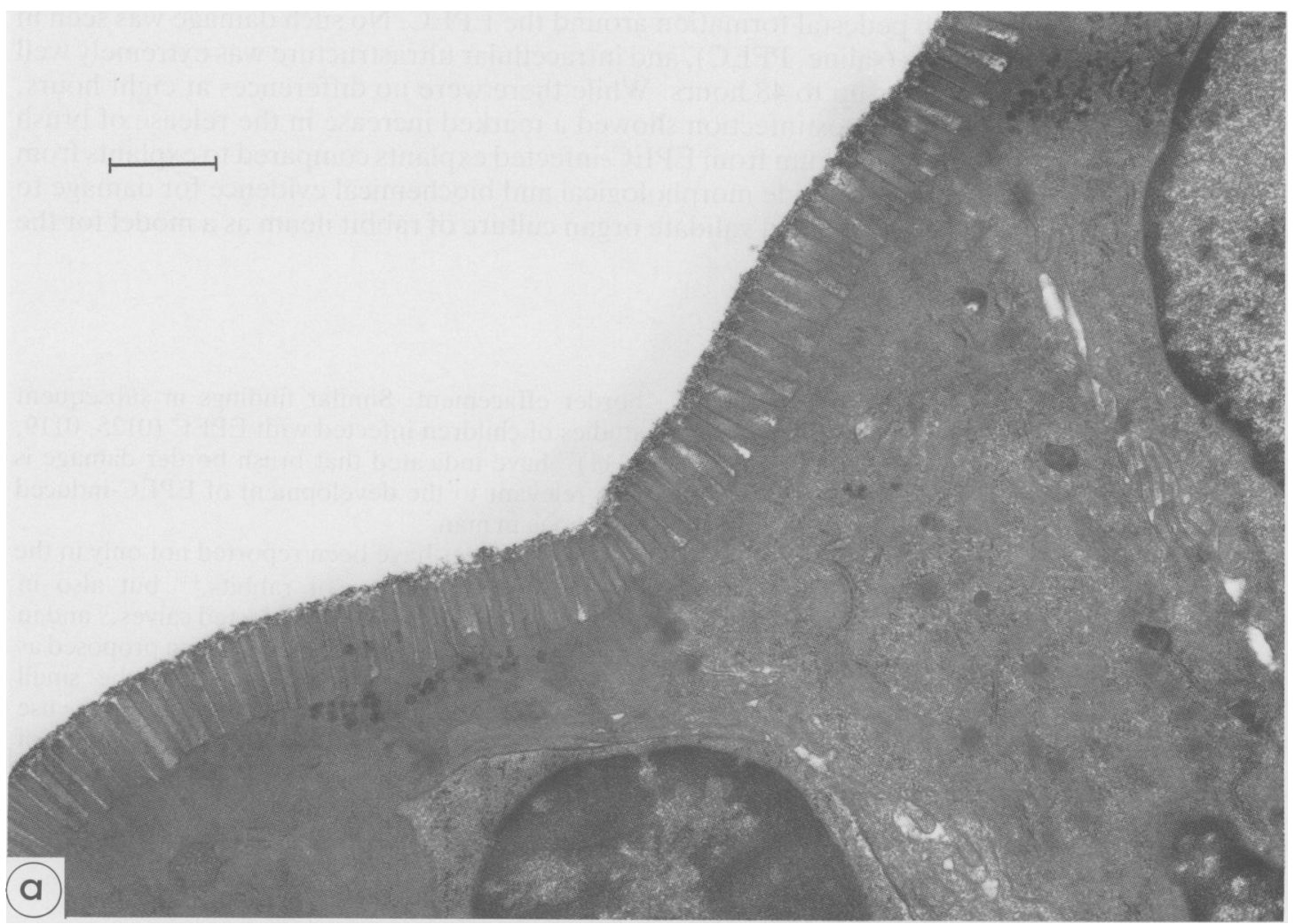

Fig. 1 Electron microscopic appearance of ileal explants afterculture. (a) Intact brush borders in explants from saline loops (control) at 48 hours. (b) Intact brush borders and adherent bacteria in explants from loops exposed to non-enteropathogenic P-fimbriate Escherichia coli at 48 hours. (c) Elongated microvilli and adherent bacteria at 18 hours, and (d) brush border effacement and pedestal formation around bacteria at 24 hours after exposure to enteropathogenic Escherichia coli. (Bars represent $(\mathrm{\mu m})$. 
cultured explants were then embedded, sectioned, and stained with Reynold's lead citrate and $1 \%(\mathrm{w} / \mathrm{v})$ uranyl acetate, and examined by use of a Philip's 301 electron microscope.

\section{BIOCHEMICAL STUDIES}

Tissue for enzyme assay was homogenised in $1 \mathrm{ml}$ sucrose medium (0.3 mmol/l sucrose, $22 \mathrm{mmol} / \mathrm{l}$ ethanol, $1 \mathrm{mmol} / 1 \mathrm{Na}_{2}$ EDTA, pH 7.4). Brush border marker enzymes in both tissue and culture medium were assayed fluorimetrically as described pre-

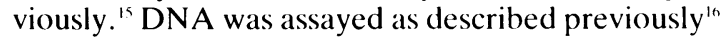
with calf thymus DNA (Sigma Type V, Poole, UK) as standard. Alkaline phosphatase was assayed fresh, then all samples were stored at $-20^{\circ} \mathrm{C}$ before further assay. Enzyme activities represent milliunits per $\mathrm{mg}$ tissue DNA unless otherwise stated. Significance of differences between mean values was determined by one-way analysis of variance and the Newman-Keuls test.

\section{Results}

\section{ULTRASTRUCTURAL STUDIES}

Ileal explants from the saline loops were maintained in culture for up to 48 hours with little evidence of damage to the brush border (Fig. 1a). Findings were similar following culture of ileal fragments exposed to non-enteropathogenic PFEC, despite adherence of these bacteria to the brush border (Fig. 1b).

After exposure of ileal mucosa to EPEC, bacteria could be seen attached to mucus overlying microvilli or goblet cells at eight hours of culture. The earliest ultrastructural changes discernable by electron microscopy, however, were observed at 18 hours, at which time EPEC were closely adherent to the surface of enterocytes at the base of microvilli, some of which were elongated (Fig. 1c). After 24 hours incubation there were large areas of bruch border effacement with obvious pedestal formation around the EPEC (Fig. 1d). No intracellular bacteria were seen and, apart from the brush border changes in EPEC explants, enterocyte ultrastructure was extremely well preserved in all preparations for up to 48 hours.

\section{BIOCHEMICAL STUDIES}

Figure 2 indicates that there was a gradual release of all three brush border marker enzymes into the culture medium from ileal explants during 24 hours after their removal from loops containing either saline or non-enteropathogenic PFEC. By contrast, while there were no differences at eight hours, between eight and 24 hours there was a marked

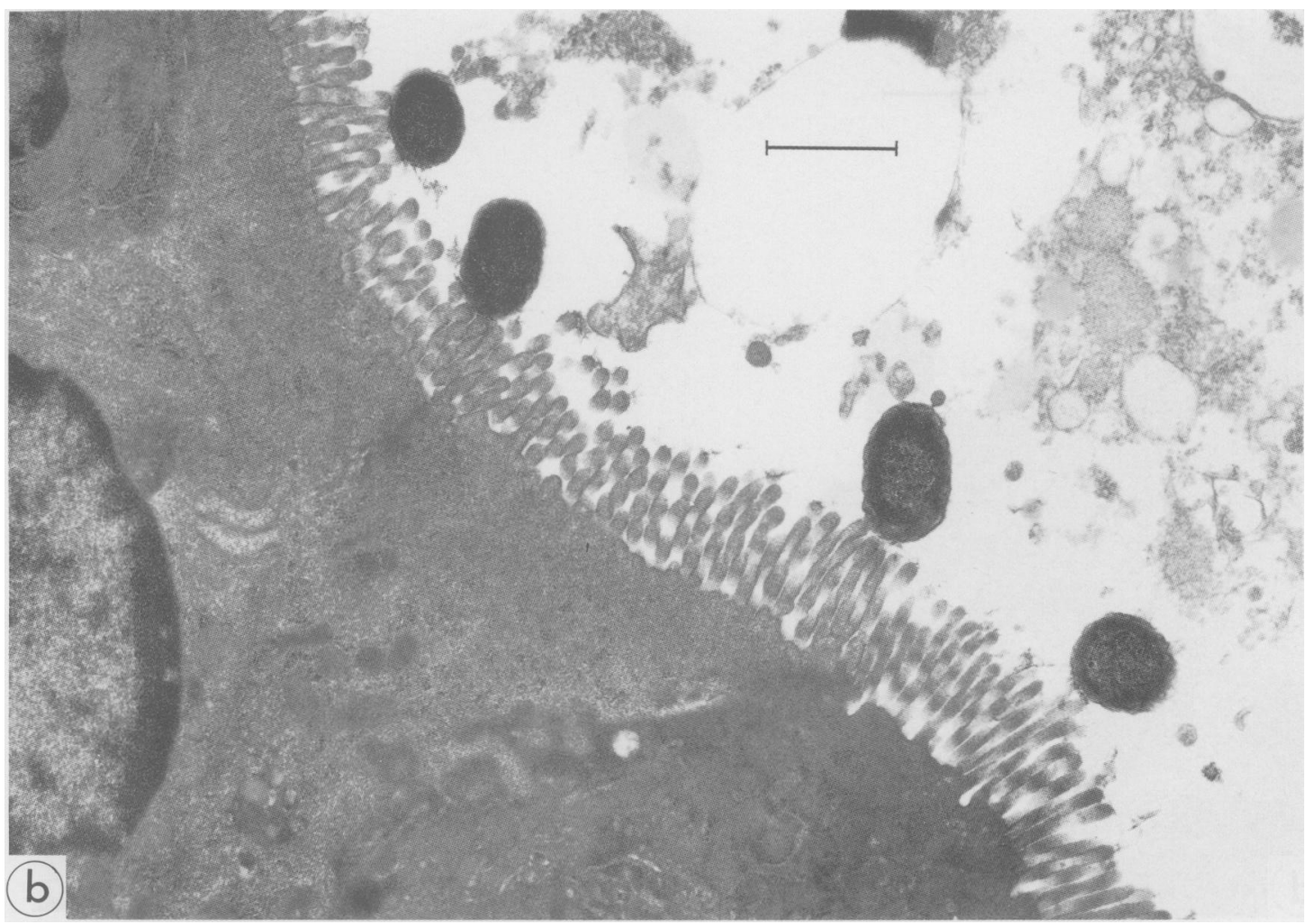




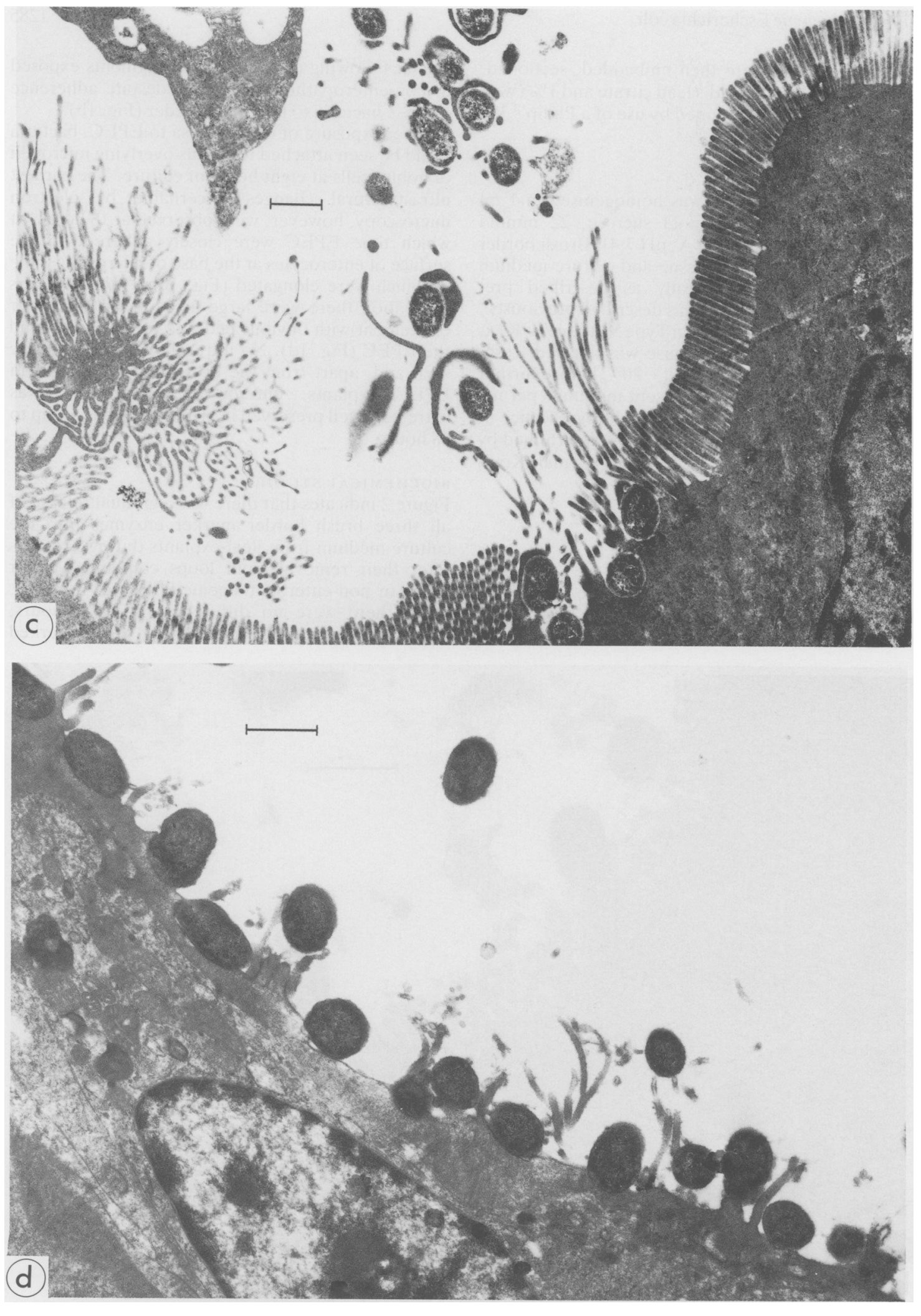

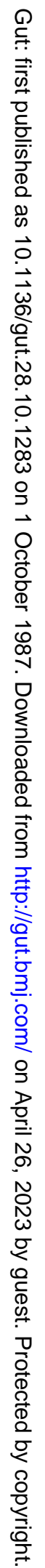




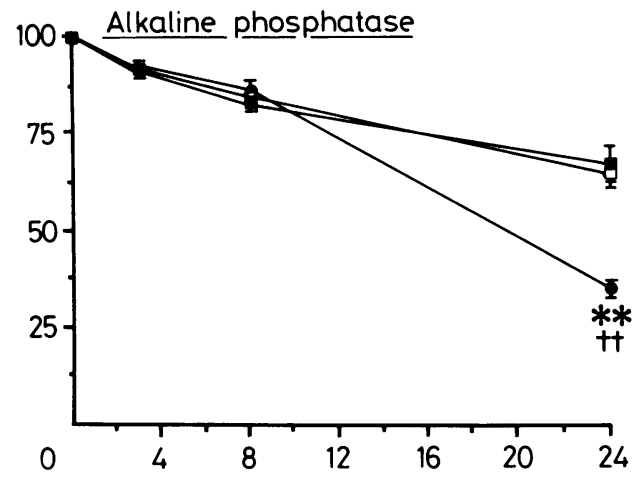

increase in the release of these enzymes from EPECinfected explants into the culture medium compared to the other two groups.

Figure 3 shows that there were no significant
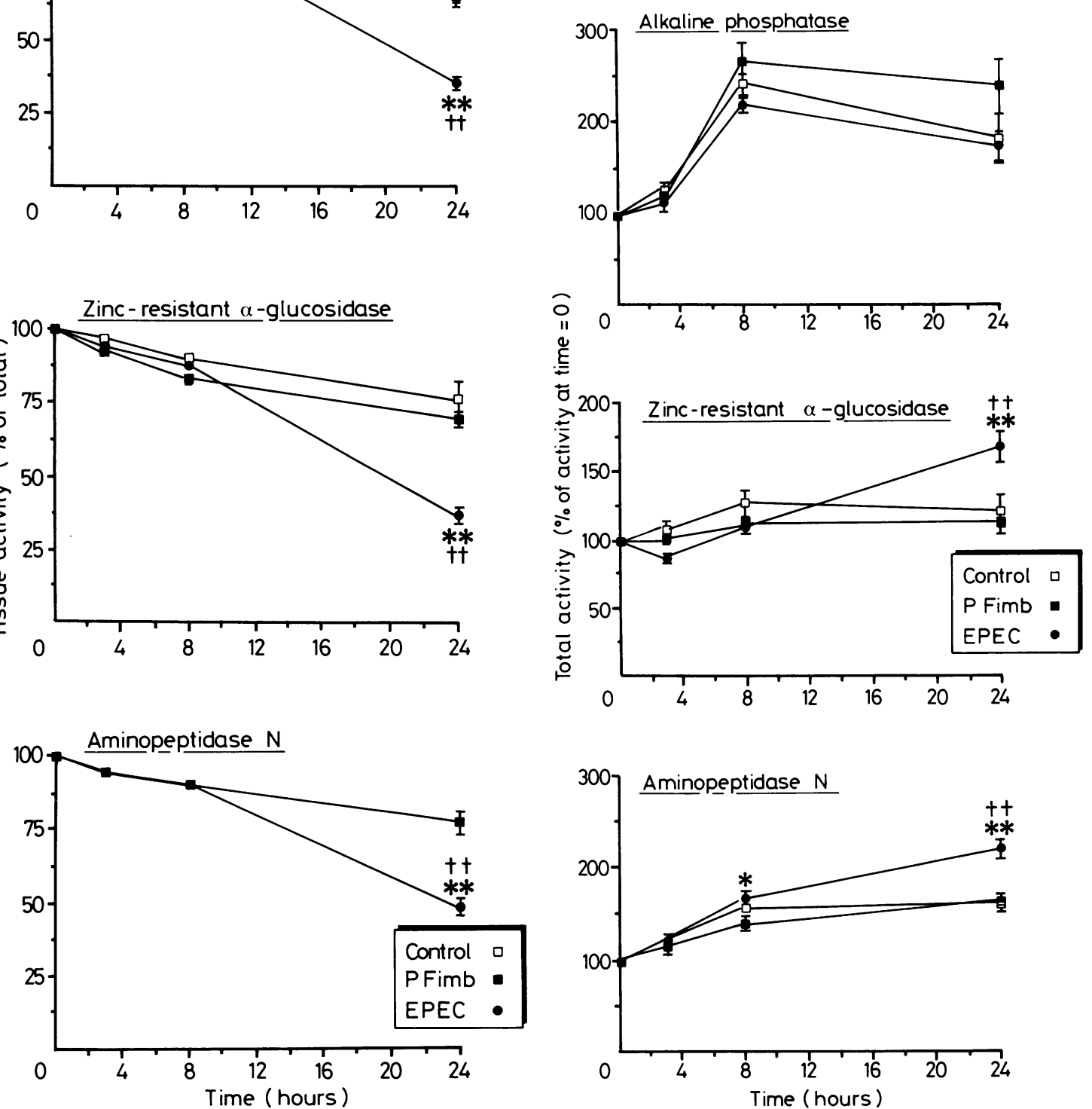

Fig. 2 Release of brush border enzymes from ileal explants into medium during culture. Data (mean \pm SEM) represent enzyme activities $(\mathrm{mU})$ in tissue expressed as percentage of total activities in tissue plus medium. Control=saline control; $P$ Fimb $=$ non-enteropathogenic $P$-fimbriate Escherichia coli; $E P E C=$ enteropathogenic E coli. Results of statistical analyses are indicated by: $E P E C \mathrm{v}$ control $++p<0 \cdot 01 ; E P E C$ $\checkmark P$ Fimb ${ }^{* *} p<0 \cdot 01$. Number of observations $(a t 4,8,24$ hours): control $(8,7,8), P$ Fimb $(7,7,7), \operatorname{EPEC}(8,7,8)$.

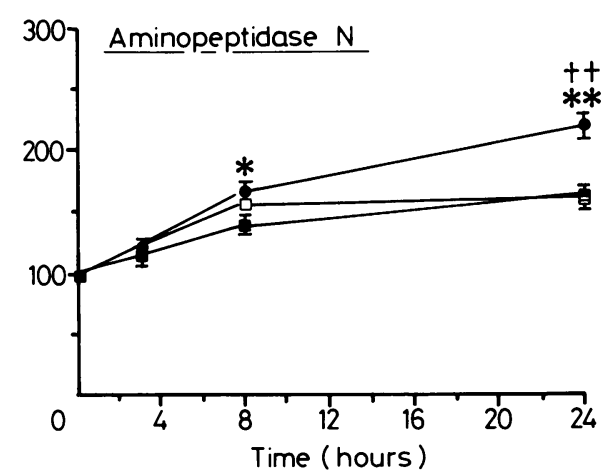

Fig. 3 Total activities of brush border enzymes during culture. Data (mean $\pm S E M)$ represent enzyme activities (mU/mg tissue DNA) in tissue plus medium expressed as percentage of activities in tissue at the beginning of culture. Control=saline control; $P$ Fimb $=$ non-enteropathogenic $P$-fimbriate E coli; $E P E C=$ enteropathogenic $\mathrm{E}$ coli. Results of statistical analyses are indicated by: EPEC $\mathrm{v}$ control $+\dagger p<0.01 ; E P E C$ v P Fimb ${ }^{*} p<0 \cdot 05,{ }^{* * *} p<0 \cdot 01$. Number of observations (at 4, 8, 24 hours): control (8, 7, 8), P Fimb (7, 7, 7), $\operatorname{EPEC}(8,7,8)$. 
differences in total alkaline phosphatase activity in the tissue and culture medium comparing the three groups during a 24 hour culture period. By contrast, total activities of zinc-resistant $\alpha$-glucosidase
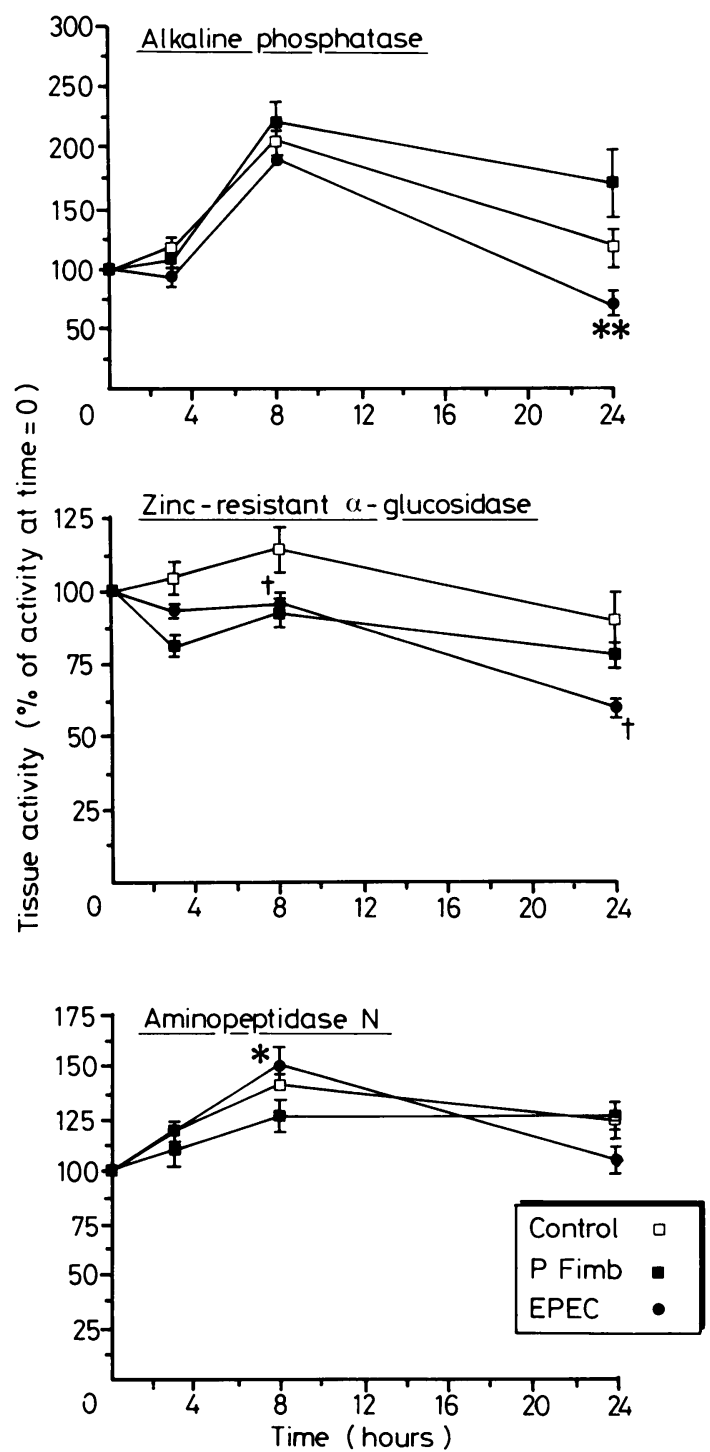

Fig. 4 Tissue activities of brush border enzymes in ileal explants during culture. Data (mean \pm SEM) represent enzyme activities ( $m U / m g$ tissue DNA) in tissue expressed as percentage of activities in tissue at the beginning of culture. Control= saline control; $P$ Fimb $=$ non-enteropathogenic $P$-fimbriate E coli; EPEC = enteropathogenic E coli. Results of statistical analyses are indicated by: EPEC v control t $p<0.05$; EPEC v P Fimb * $p<0.05$, ** $p<0.01$. Number of observations (at 4, 8, 24 hours): control $(8,7,8)$, P Fimb $(7,7,7), \operatorname{EPEC}(8,7,8)$. (maltase) and aminopeptidase $\mathrm{N}$ in the EPEC group increased between eight and 24 hours to mean values that were significantly higher than those in the other two groups.

Figure 4 shows that in explants from saline and non-enteropathogenic PFEC loops, tissue activities of alkaline phosphatase approximately paralleled total alkaline phosphatase activities during the culture period (Fig. 3). In these two control groups, tissue activities increased during the initial eight hours and then declined relatively slowly to activities at 24 hours which remained above those at the beginning of the culture period. In contrast, tissue alkaline phosphatase in the EPEC group dropped between eight and 24 hours to a mean activity below that at the beginning of the culture period. Similarly, while tissue activities of zinc-resistant $\alpha$-glucosidase and aminopeptidase $\mathrm{N}$ in the two control groups (Fig. 4) paralleled total enzyme activities in tissue and medium (Fig. 3) this was not the case for the EPEC group. Tissue activities in the EPEC group dropped markedly between eight and 24 hours (Fig. 4) while total activities increased (Fig. 3). These findings are reflected in the tissue to total enzyme activities shown in Fig. 2, and are consistent with an enhanced loss of these brush border enzymes from EPEC explants into the medium.

Assay of bacterial suspensions indicated that enzyme activities of bacterial origin did not interfere with the interpretation of any of these biochemical data.

\section{Discussion}

This investigation has shown that organ culture of rabbit ileal explants can provide a suitable model for the investigation of EPEC-induced damage to the small intestine. Ultrastructural studies identified the specific brush border abnormalities which characterise this infection, while biochemical studies provided clear supportive evidence for damage to the microvillus membrane.

In order to exclude potential non-specific consequences of bacterial infection of explant tissue it was essential to include adequate controls in this model system. This was achieved by the examination of the effects of a non-enteropathogenic P-fimbriate Escherichia coli (PFEC), a bacterium which could adhere to the mucosal surface but which did not have the capability to disrupt enterocyte brush borders. The lack of ultrastructural damage to the brush border by PFEC, in addition to the similarities comparing the biochemical results in the PFEC and saline control groups, emphasised the specificity of the changes with EPEC. Incubation in ileal loops was used as an initial step in this study to ensure adhesion 
of bacteria to brush borders before organ culture; however, we have achieved comparable results in subsequent studies in which bacteria have been added directly to the culture medium.

The experiments in this study indicate that there may be a considerable delay between infection with EPEC and the overt manifestation of brush border damage. The biochemical studies, which can provide a relatively sensitive assessment of mucosal injury, were unable to detect any abnormalities before eight hours of culture, whereas at 24 hours there was definite biochemical evidence for brush border damage. Similarly, the earliest ultrastructural changes, comprising elongation of microvilli and attachment of bacteria at their base, were documented at 18 hours and were relatively minor compared with the changes at 24 hours. There were conspicuous areas of brush border effacement at 24 hours, and the luminal surface of the damaged plasma membrane appeared to be moulded to form pedestals around individual EPEC. These changes have been described in EPEC infection of man, ${ }^{5-7}$ rabbits, ${ }^{411}$ and pigs, ${ }^{12}$ and are considered to be important and characteristic features of the disease. At present, however, it is not certain whether an apparent delay in the development of mucosal damage after infection is related to time for bacterial synthesis of factor(s) responsible for pathogenicity, time for consequential tissue damage, or to bacterial concentration and hence time for organism multiplication. In addition, little is known of how EPEC penetrate the mucin layer, or why EPEC appear to adhere to the base of microvilli rather than their tips. Nevertheless, it does appear that this close approximation between bacteria and the enterocyte surface at the base of microvilli is necessary to induce the specific ultrastructural changes characteristic of EPEC infection.

The most sensitive biochemical indication of mucosal damage was provided by the assessment of the proportions of brush border enzyme activities in the tissue and culture medium throughout the culture period. In the saline and PFEC control groups, the gradual decline in the proportion of tissue to total activities of all three enzymes examined was consistent with the normal release of brush border enzymes from the explants into the medium during culture. ${ }^{17}$ In marked contrast, EPEC infection was associated with a considerable fall in this ratio which was indicative of enhanced release of these enzymes from the mucosa between eight and 24 hours of culture.

Throughout a 24 hour culture period there were no differences in total alkaline phosphatase activity in the tissue and culture medium comparing the EPEC and control groups. Consequently, while increased synthesis could have been masked by increased degradation, at present there is no indication of an alteration in the rate of synthesis of alkaline phosphatase by enterocytes during infection with EPEC. This contrasts with data for zinc-resistant $\alpha$-glucosidase and aminopeptidase $\mathrm{N}$, which at 24 hours showed significantly higher total activities of these enzymes in the EPEC compared with the other two groups. This could be indicative of an enhanced rate of synthesis of these proteins which might occur in response to increased loss of these enzymes from the microvillus membrane. Enhanced synthesis could explain the relatively modest decreases in tissue activities of zinc resistant $\alpha$-glucosidase and aminopeptidase $\mathrm{N}$ observed at 24 hours, despite increased loss of these brush border enzymes from EPEC explants into the medium. The subcellular localisation of these enzyme activities in tissue after culture has not been determined; however, the morphological damage to the brush border at 24 hours suggests that the proportion of tissue enzyme activity that is in transit to the microvillus membrane may be relatively higher in the EPEC than in the control groups. These biochemical findings emphasise that the changes in the EPEC explants may be relatively early compared with those seen in clinical disease where tissue activities of brush border enzymes can be severely reduced.'

This investigation has provided morphological and biochemical evidence for damage to the microvillus membrane by EPEC, and suggests that culture of rabbit ileal explants should prove a valuable tool for the investigation of the molecular biology of EPECpathogenicity.

The authors gratefully acknowledge the financial support from the Wellcome Trust.

\section{References}

1 Candy DCA, McNeish AS. Human Escherichia coli diarrhoea. Arch Dis Child 1984; 59: 395-6.

2 Dean AG, Ching YC, Williams RA, Harden LB. Test for $E$ coli enterotoxin using infant mice: application in a study of diarrhea in children in Honolulu. $J$ Infect Dis 1972; 125: 407-11.

3 Szereny B. Experimental shigella keratoconjunctivitis: a preliminary report. Acta Microbiol Acad Sci Hung 1955; 2: 293-6.

4 Cantey JR, Blake RK. Diarrhea due to Escherichia coli in the rabbit: a novel mechanism. J Infect Dis 1977; 135: 454-62.

5 Ulshen MH, Rollo JL. Pathogenesis of Escherichia coli gastroenteritis in man - another mechanism. $N$ Engl $J$ Med 1980; 302: 99-101.

6 Rothbaum R, McAdams AJ, Giannella RA, Partin JC. A clinicopathologic study of enterocyte-adherent Escherichia coli. Gastroenterology 1982; 83: 441-54. 
7 Taylor CJ, Hart CA, Batt RM, McDougall C, McLean L. Ultrastructural and biochemical changes in human jejunal mucosa associated with enteropathogenic Escherichia coli (0111) infection.J Pediatr Gastroenterol Nutr 1986; 5: 70-3.

8 Neter E. Enteritis due to enteropathogenic Escherichia coli. Present day status and unsolved problems. J Pediatr 1959; 55: 223-39.

9 Edelman R, Levine MM. Summary of a workshop on enteropathogenic Escherichia coli. J Infect Dis 1983; 147: $1108-18$.

10 Peeters JE, Charlier GJ, Halen PH. Pathogenicity of attaching effacing enteropathogenic Escherichia coli isolated from diarrheic suckling and weanling rabbits for newborn rabbits. Infect Immun 1984; 46: 690-6.

11 Hall GA, Reynolds DJ, Chanter N, et al. Dysentery caused by Escherichia coli (S102-9) in calves: Natural and experimental disease. Vet Pathol 1985: 22: $1.56-$ 63.

12 Tzipori S, Robins-Browne RM, Gonis G, Hayes J,
Withers M, McCartney E. Enteropathogenic Escherichia coli enteritis: evaluation of the gnotobiotic pig as a model of the human infection. Gut 1985; 26: 57()$-8$.

13 Browning TH, Trier JS. Organ culture of mucosal biopsies of human small intestine. J Clin Invest 1969; 48: 1423-32.

14 Jos J, Lenoir G, de Ritis G, Rey J. In vitro pathogenetic studies of coeliac disease. Effects of protein digests on coeliac intestinal biopsy specimens maintained in organ culture for 48 hours. Scand J Gastroenterol 1975; 10: $121-8$.

15 Batt RM, Peters TJ. Subcellular fractionation studies on peroral jejunal biopsies from the dog. Res Vet Sci 1978; 25: $94-100$.

16 Labarca C, Paigen K. A simple rapid and sensitive DNA assay procedure. Anal Biochem 1980; 102: 344-52.

17 Scott J, Peters TJ. Protection of epithelial function in human jejunum cultured with hydrocortisone. $A m J$ Physiol 1983; 244: G532-G540. 